\title{
The Ultimatum Game, Distribution Of Income And Re-Distributive Policy
}

James R. Seldon, Thompson Rivers University, Canada Peter Tsigaris, Thompson Rivers University, Canada

\begin{abstract}
In this paper we examine the ultimatum game's income distribution and efficiency implications and modify the game to investigate the impact of re-distributional policies imposed on the parties.
\end{abstract}

Keywords: Ultimatum game, dictator game, income distribution, re-distribution policy.

\section{INTRODUCTION}

$\mathrm{t}$ is well known that games in which there is an ultimatum can generate devastating outcomes for both parties. A company's last contract offer to a labour union may lead to rejection and a strike, while in the political arena, spurning a final offer might lead to escalation of violence and even war. Rejections of final offers clearly make both parties worse off. Why then do they appear to be considerably more common in practice than might be anticipated? The usual explanation advanced in the literature is that offers considered unfair by responders to ultimata are apt to be rejected. However, there seems to be no consensus on how fairness perceptions are established or on the extent to which they reflect social pressures and thus constraints on choice rather than inherent characteristics of objective functions.

To obtain experimental evidence and motivate discussion on fairness and bargaining issues, a simple exercise known as the ultimatum game was devised by Guth et al (1982) and in one form or another the ultimatum game remains one of the most popular experiments. To the best of our knowledge, the differences in income distributions and efficiency levels between the basic game and one including a social justice re-distribution of income scheme have to date not been explored in the literature. To explore these issues we administered the ultimatum game as modified by Dickinson (2002) in our introductory microeconomics classroom. In the present paper we use the results to explore the aggregate social welfare implications of the game, investigating fairness in terms of the income distribution that arises from the game and expanding the exercise to consider the impact of redistributional policies imposed on the parties.

\section{THE ULTIMATUM GAME}

In the ultimatum game, individuals are paired anonymously. One player, the "proposer," is told to imagine $\mathrm{s} /$ he has just won a lottery (without having bought a ticket) or been given (or perhaps has just found) a specific sum of money and is asked by the experimenter to offer a share of the windfall to a second player, the "responder." Both proposers and responders are told that if the offer is accepted, the responder is to be given the offer amount and the proposer will get to keep the remainder; but if the responder rejects the offer, both players receive nothing.

If the players are informed, self-interested and rational, the predicted outcome of this two-person game is for a positive but minimal transfer of wealth. ${ }^{1}$ Since rejection means that a responder is guaranteed to receive nothing, the one-shot equilibrium strategy is to accept any positive amount the proposer offers. The proposer, given the responder's dominant strategy, thus will rationally offer the smallest positive amount possible. ${ }^{2}$

\footnotetext{
${ }^{1}$ The unique subgame perfect equilibrium is for the proposer to offer nothing and the responder to accept this.

${ }^{2}$ In repeated games with individuals sometimes as responders and sometimes as proposers it would be reasonable for selfinterested behaviour to result in tit-for tat behaviour and an ultimate sharing of windfalls.
} 
Figure 1 illustrates the payoffs. The proposer is given (conditionally) ten dollars and is required to make an offer to the responder of at least (arbitrarily) one dollar. If the responder accepts, each receives the respective payout. If the responder rejects the offer, neither receives anything. Since the actual offer is a matter of proposer choice, the equal-share option is but one alternative to the minimum and is shown merely for purposes of illustrating the thought processes in which one would expect a proposer to engage. Nash equilibrium is shown in the top right hand cell with strategies for the proposer to offer the smallest possible amount (in this example, one dollar) and for the responder to accept that amount.

Figure 1: Payoffs for Proposer and Responder

\begin{tabular}{|l|l|c|c|c|}
\hline \multicolumn{2}{|c|}{ Pie Size: $\$ \mathbf{1 0}$} & \multicolumn{3}{c|}{ Proposer } \\
\hline \multirow{3}{*}{ Responder } & Strategy & Share equally & Share more & Minimal offer \\
\cline { 2 - 5 } & Accept & $\$ 5, \$ 5$ & $\$ 7, \$ 3$ & $\$ 9, \$ 1$ \\
\cline { 2 - 5 } & Reject & 0,0 & 0,0 & 0,0 \\
\hline
\end{tabular}

Contrary to the 'selfish' model's predictions, the Nash equilibrium outcome in settings such as this has rarely materialized in numerous experimental studies across nations, with different lottery sizes, and employing various experimental procedures. The most common outcome has been for proposers to offer considerably more generous amounts than the minimum but rarely to equally share the pie. See for example Guth et al., (1982), Roth (1995) and Camerer and Thaler (1995).

Most experimental studies indicate offers are almost never above 50 percent and the average offers are in the $25-50$ percent range. Responders have shown themselves most likely to reject ungenerous offers, particularly those less than 20 percent of the lottery. Also the evidence indicates that the probability of rejecting offers tends to decrease with increasing offers. ${ }^{3}$ The main conclusion in the literature thus has been that (at least within the context of the game) the rational self-interest model of decision-making fails: individuals do not act to maximize their own economic well being.

An explanation provided by the literature is that individuals have preference structures defined not only over their own well being but also over fairness considerations. Rabin (1993) and recently Falk and Fischbacher (2006) developed a model of reciprocity in which fair intentions are rewarded while unfair ones are punished. In Fehr and Schmidt (1999), individuals are modelled as caring about fairness through an aversion towards what they call self-centered inequality. ${ }^{4}$

The aim of the present paper is to examine the income distribution and level arising from the basic ultimatum game and to compare those outcomes with counterparts arising from the game when there is a redistributional mechanism in place. In the next sections, we present the results of the game without a re-distribution policy, followed by the results with such a policy in place. We conclude with discussion of our findings.

\section{THE CLASSROOM GAME WITHOUT A TAX/TRANSFER SYSTEM}

On October 13th 2006, seventeen pairs of microeconomics principles students participated in a one-round combined ultimatum and dictator game with a $\$ 10$ lottery allocation. The dictator game was played implicitly by having the proposers asked to record on their earnings sheets the offers they would make if responders, instead of being allowed to reject offers, were forced to accept any decision made by the proposer. Responders were not told this question was being asked, and proposers were aware that was the case. Table 1 summarizes offers:

\footnotetext{
${ }^{3}$ For a literature review see Fehr and Schnidt (1999).

${ }^{4}$ See also Andreoni and Miller (2001), and Bolton and Ockenfels (1997).
} 
Table 1: Mean, Median and Mode Offers

\begin{tabular}{|l|c|c|}
\hline \multicolumn{1}{|c|}{ Statistics } & Ultimatum Game & Dictator Game \\
\hline Mean Offer & $\$ 3.70$ & $\$ 1.35$ \\
\hline Mode & 4.00 & 0.00 \\
\hline Median & 4.00 & 1.00 \\
\hline Minimum & 2.00 & 0.00 \\
\hline Maximum & 6.00 & 3.00 \\
\hline
\end{tabular}

The mean offer in the ultimatum game was $\$ 3.70$ (median $\$ 4.00$ ) while in the dictator game it was $\$ 1.35$ (median \$1). The two population means were significantly different at the one percent level.

The difference in the averages between the two games represents the extra price proposers were prepared to pay for fear of being rejected, and thus is in effect a risk premium; see Forsythe et al. (1994). The fact that Figure 1 shows a payoff matrix in which the cooperative solution is in fact selected by the proposer of course means that the conventional model of consumer choice under conditions of certainty does not necessarily provide the appropriate predictions of utility-maximizing behaviour.

Further, since proposers might have been induced to offer more than allowable minimum either by internal fairness considerations or by external social pressures, whether outcomes would be different if responders were informed about the nature of the dictator game (and proposers in turn were told that responders would be made aware) is a potentially fruitful area for further investigation. Hoffman et al (1994) found in a double-blind framework where both subject-subject and subject-experimenter were anonymous that the dictator game generated a higher level of self interest, suggesting that the possibility of social pressure deserves to be taken seriously. List (2007) allowed dictators to take money from the other player and the experiments indicated that fewer participants are willing to give money away providing support to the self interest model. A further possibility to be considered, of course, is that despite the instructions, game-players implicitly see themselves participating in one component of a multi-period sequence of games. Figure 2 shows the histograms for the two games.

With knowledge of the ten dollar windfall, responders were asked to identify minimum acceptable offers; that is, amounts below which they would choose to reject the offer. Table 2 shows the results.

Table 2: Statistics on Acceptable Offers ${ }^{5}$

\begin{tabular}{|l|c|}
\hline \multicolumn{1}{|c|}{ Statistics on } & Ultimatum Game \\
\hline Mean Acceptable Offer & $\$ 3.72$ \\
\hline Mode & 4.00 \\
\hline Median & 4.00 \\
\hline Minimum & 2.00 \\
\hline Maximum & 5.00 \\
\hline
\end{tabular}

The mean minimum acceptable offer was $\$ 3.72$, almost identical to the mean offer recorded in Table 1 . Combining offer and acceptance responses, two offers exceeded 50 percent and both were accepted. Seven offers were in the $40-49$ percent range and only one of these was rejected. Finally, there were eight offers of less than 40 percent, half of which were rejected. No offers were for less than 20 percent. Overall, then, five out of seventeen offers ( 29 percent) were rejected by responders.

\footnotetext{
${ }^{5}$ These results are slightly biased in the upwards direction because the responders were aware of the offer when answering the question on their minimum acceptable offer. However, proposers were not aware that responders were being asked to identify minimum acceptable offers.
} 


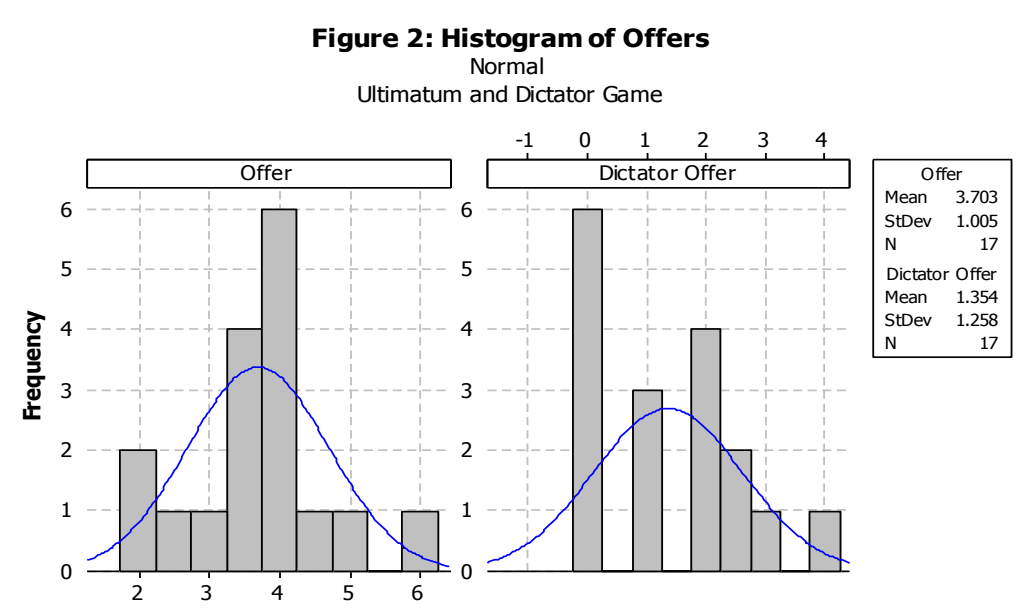

The average earnings for a proposer is a combination of the earnings of those being rejected and thus earning nothing and those whose earnings are net of the offer of the accepted proposals. While the responder's average earnings are the total earnings/offers that are accepted plus zero for those who rejected the offers. Ultimatum game proposers on average earned $\$ 4.29$ (the sum of their earnings divided by number of proposers) with responders earning an average of $\$ 2.76$. In the dictator game, proposers' average earnings were almost double at $\$ 8.65$, while the responders' were approximately halved at $\$ 1.35$. In the aggregate, one can observe a substantial loss in total wealth in the ultimatum game, since the average per-game earnings in the ultimatum setting were \$7.06, while under dictatorial conditions they were ten dollars.

Application of the Potential Pareto criterion to the above results would of course indicate clear superiority of dictatorship. However, given the widely differing income distributions emerging from the two scenarios it is by no means certain a collective (societal) sense of fairness would not lead to the judgement that the more equal distribution of income would be preferable despite the lower average earnings of group members.

The initial value of the potential payouts totalled $\$ 170$ ( $\$ 10$ times 17 pairs of students.) In the dictator game, the total was constrained to remain at $\$ 170$, while in the ultimatum game it fell to $\$ 120$ (\$7.06 times 17) because rejected offers yielded nothing to either party. The difference between these outcomes represents a huge sacrifice of the total value of the economic pie.

Although the motives of responders - who, after all, are in effect hoping to receive a larger rather than a smaller free lunch - remain a matter for debate, one plausible explanation of their behaviour is that when faced with an offer considered unfair, they resolve in a version of tit-for-tat strategy to bring the proposer - an otherwise identical counterpart with the good fortune to have been a proposer rather than a responder - to the same income or social class to which the responder will belong with the rejection.

Figure 3 shows graphically the income distributions resulting from the ultimatum and dictator games, the equal-income case, and the setting in which individuals receiving the initial endowments are allowed to keep those endowments without transferring any funds to others. The solid line shows the income distribution in an initial allocation in which half of the subjects receive 10 dollars and the other half receive nothing. The initial distribution consists of those that have (given the randomness of the game, the lucky) and those that have not (the unlucky). The dashed line shows the income distribution given perfect equality (everyone is given 5 dollars) while the dotted line shows the ultimatum game results and the final mixed dot and dash line shows the result of the dictator game. 


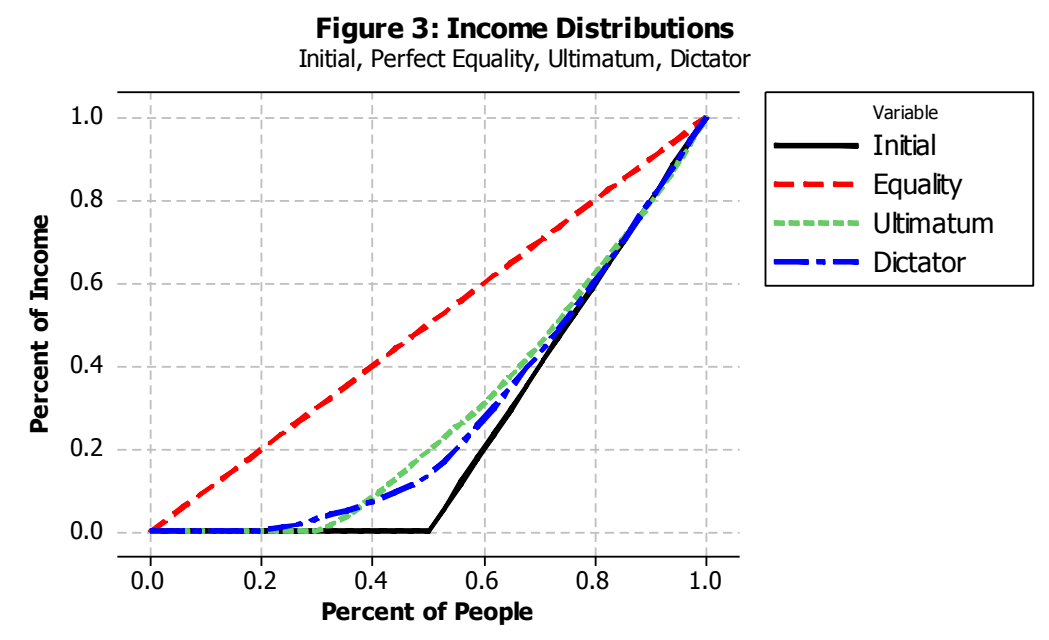

Lorenz Curves

It is apparent from Figure 3 that the income distribution improves in both the ultimatum and in the dictator game relative to the initial income distribution. Furthermore, one can observe from the figure that there are more individuals receiving nothing in the ultimatum game than the dictator game. Ten individuals earned nothing in the ultimatum game while only four people earned nothing in the dictator game, although two additional individuals were given one cent each in the dictator game.

To quantify and compare the degrees of inequality we use the Gini coefficient, defined in the traditional way as the ratio of the two areas in the unit box. The area between the perfect equality of the lottery (the area below the dashed line when each individual is initially allocated 5 dollars) and the area above the line in each respective case (Area $\mathrm{A}$ ) relative to the area below the perfect equality line (i.e., Area $=\mathrm{A}+\mathrm{B}=0.5$ ). The area below the perfect equality line (i.e. $\mathrm{A}+\mathrm{B}$ ) is equal to 0.5 by construction. The Gini coefficient thus lies in the $0-1$ interval. A zero coefficient implies perfect equality, while a coefficient equal to unity would imply perfect inequality (all wealth in the hands of a single individual.) Table 3 presents the Gini coefficients for the four alternatives.

Table 3: Gini Coefficients under Alternative Cases

\begin{tabular}{|l|c|}
\hline \multicolumn{1}{|c|}{ Case } & Gini Index \\
\hline Perfect Equality & 0.00 \\
\hline Ultimatum Experiment & 0.41 \\
\hline Dictator Experiment & 0.43 \\
\hline Initial Case & 0.50 \\
\hline Perfect Inequality & 1.00 \\
\hline
\end{tabular}

Two particular results are worth mentioning. First, the income distribution under both games improves in terms of reducing inequality relative to the initial allocation. Nevertheless, the resulting distributions do not approach the case of perfect equality even though this was a possibility with each proposer offering five dollars and each responder accepting. Second, the income distribution resulting from the ultimatum game is only slightly more equal than in the dictator game. Thus, the ability to reject offers does little to improve ${ }^{6}$ the income distribution. Furthermore, the reduction in efficiency relative to the dictator game is large since there is almost a thirty percent loss in output.

${ }^{6}$ In general, of course, there is no justification for deeming a more equal distribution of wealth preferable to an unequal one, particularly if it is achieved by redistributional means. In the game situation, however, where the parties gain wealth and become rich(er) or poor(er) entirely by chance, that perspective is surely appropriate. 


\section{THE GAME WITH A TAX/TRANSFER SYSTEM}

In this section we consider ultimatum and dictator game behavior with a social justice system in place. In this second experiment we force a re-distribution amongst the parties involved. To begin the game, the experimenter (the social planner) announces that the lottery will be given to the proposer but informs both proposers and responders that under an enforceable tax/transfer scheme, a proportion of the windfall will automatically be transferred to the responders.

It seems reasonable to expect that with informed players if the policy was for an equal split of the initial allocation there would be no offers made by proposers and no rejections by responders, and that the same choices would follow if the tax rate were in excess of one half. Thus, transfer schemes involving transfer of less than fifty per cent are the ones of practical interest.

The game is then played with the post-tax lottery in the same way as before. The responder could again accept or reject the offer and in the case of rejection, neither party would receive any payout. This implies that responders have the power to reject the tax/transfer or social justice system along with the offer. In cases where the responder accepts the offer, s/he gets the transfer plus the offer while the proposer get to keep the after-tax lottery minus the offer.

In the modified dictator game, the responder must accept whatever offer is made and cannot reject the social transfer policy that has been enforced upon him. The dictator game was once again played implicitly by asking proposers to secretly to record on their earnings sheets the amounts they would offer to the responder from after tax dollars if there was no possibility that the offer would be rejected.

On October $30^{\text {th }} 2006$ another seventeen pairs of microeconomics principles students participated in a oneround ultimatum and dictator game, again with an initial $\$ 10$ lottery allocation but this time with a thirty percent tax/transfer scheme. Table 4 presents comparative outcomes:

Table 4: Mean, Median and Mode Offers with and without Tax System

\begin{tabular}{|l|c|c|c|c|}
\hline & $\begin{array}{c}\text { Ultimatum Game } \\
\text { Without Taxes }\end{array}$ & $\begin{array}{c}\text { Ultimatum Game } \\
\text { With Taxes }\end{array}$ & $\begin{array}{c}\text { Dictator Game } \\
\text { Without taxes }\end{array}$ & $\begin{array}{c}\text { Dictator Game } \\
\text { With taxes }\end{array}$ \\
\hline Mean Offer & $\$ 3.70$ & $\$ 1.82$ & $\$ 1.35$ & $\$ 0.62$ \\
\hline Mode & $\$ 4.00$ & $\$ 2.00$ & $\$ 0.00$ & $\$ 0.00$ \\
\hline Median & $\$ 4.00$ & $\$ 2.00$ & $\$ 1.00$ & $\$ 0.25$ \\
\hline
\end{tabular}

The mean offer in the modified ultimatum game was $\$ 1.82$ (median $\$ 2.00$ ) while in the dictator game the average offer was $\$ 0.62$ (median $\$ 0.25$ ). As expected, the mean, mode and median offers all were lower with a redistributive tax/transfer system in place relative to the case without such a system. However, there were now only two offers rejected out of seventeen offers made, presumably because rejection meant not only the sacrifice of the offer itself but of the thirty per cent transfer. The overall effect was a rejection rate less than half the 29 percent rate in the previous case and a sizeable gain in wealth relative to the case without tax/transfer. Figure 4 shows the distribution of offers with a tax/transfer scheme in place.

Proposers on average earned $\$ 4.44$ compared with $\$ 4.29$ in the previous case without a re-distribution system, while responders earned on average $\$ 4.38$ versus $\$ 2.76$ without the tax/transfer system. Thus, both earned on average more than the case without the tax/transfer system but responders gained significantly more.

In the dictator game, the proposers' average earnings now were $\$ 6.38$, a decline from $\$ 8.65$ in the absence of a tax/transfer arrangement, while responders received $\$ 3.62$ compared with $\$ 1.35$. Thus, the effect of the three dollar tax was to reduce offers by an average of less than one dollar, suggesting either that a fairness explanation requires substantial qualification or greater attention might be paid to the rejection-risk premium. 


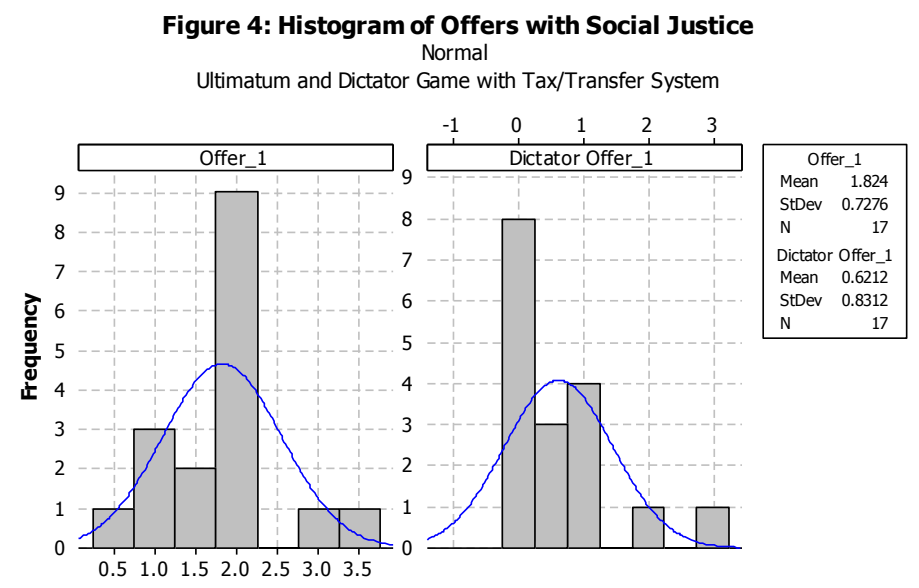

In the aggregate there remained an aggregate loss of wealth in the ultimatum game since average earnings in the ultimatum game summed to $\$ 8.82$, while in the dictator game there was (could be) no loss of output.

In sum, the same qualitative results are observed in this case as in the previous version of the game. There is a reduction in inequality even with a tax/transfer system in place due to the generosity - or perhaps risk aversion on the part of the proposers. The reduction in inequality is not as large as the previous case since the tax/transfer system does most of the reduction of inequality. Furthermore, the income distribution of the ultimatum game marginally improves in relation to the dictator game again in this case as was the case in the previous system.

Table 5 shows the Gini index under the new rules.

Table 5: Gini Coefficient under the Different Cases

\begin{tabular}{|l|c|}
\hline \multicolumn{1}{|c|}{ Case } & Gini Index \\
\hline Perfect Equality & 0.00 \\
\hline Ultimatum Experiment & 0.172 \\
\hline Dictator Experiment & 0.179 \\
\hline Initial Case with 7 - 3 distribution & 0.200 \\
\hline Perfect Inequality & 1.00 \\
\hline
\end{tabular}

Clearly, the degree of inequality has been reduced from the interval $[0.4-0.5]$ in the case where the redistribution was left to the public's generosity (or guilt, or social pressure) to a level of [0.17 - 0.20] with a governmental re-distributional policy. The reduction in inequity under a system with a tax/transfer scheme in place comes with a smaller loss in wealth relative to the system without such a scheme.

It is important to note the responder had the power to reject the offers and the tax/transfer system imposed on him by the external body if he deemed the overall impact as unfair. However, rejection occurred less often than in the previous case and hence there was less output sacrifice associated with a reduction in inequality.

\section{DISCUSSION AND CONCLUSIONS}

Let us assume that individuals care about equity and the proposer and responder have utility functions as those developed by Fehr and Schmidt (1999). Individuals get direct utility from monetary payoffs but also get disutility from inequity. Individuals dislike perceived inequitable outcomes and are willing to sacrifice some of the monetary payoff to reduce this inequity. Fehr and Schmidt assume that inequity aversion is self-centered implying that people care only about how their monetary payoff deviates from others and not about the inequity that exists among the other people. The proposer's utility is given below: 


$$
\mathrm{U}_{\mathrm{P}}=\mathrm{y}_{\mathrm{P}}-\alpha_{\mathrm{p}} \operatorname{Max}\left|\mathrm{y}_{\mathrm{R}}-\mathrm{y}_{\mathrm{P}}, 0\right|-\beta_{\mathrm{P}} \operatorname{Max}\left|\mathrm{y}_{\mathrm{P}}-\mathrm{y}_{\mathrm{R}}, 0\right|
$$

Where $\mathrm{y}_{\mathrm{P}}$ is the money kept by the proposer, $\mathrm{y}_{\mathrm{R}}$ is the money accepted by the responder. Assuming the proposer offers a share $s$ of one dollar to the responder, the former will get utility, provided the latter accepts the offer, equal to:

$$
\mathrm{U}_{\mathrm{P}}=1-\mathrm{s}-\alpha_{\mathrm{p}} \operatorname{Max}|2 \mathrm{~s}-1,0|-\beta_{\mathrm{P}} \operatorname{Max}|1-2 \mathrm{~s}, 0|
$$

The first term in the above utility is the direct benefit that accrues to the proposer given that the responder accepts the offer. The second term measures the disutility from what Fehr and Schmidt call disadvantageous inequity. This disutility to the proposer arises when responder gets a larger share than one half of the share, namely when:. $y_{R}-y_{P}=2 s-1>0$. This rarely happens in experimental games. The last term is the disutility from advantageous inequity. Here the disutility arises when the share that the proposer keeps is greater than the responder's share of the pie: $y_{P}-y_{R}=1-2 s>0$. It is also assumed that $\alpha_{p} \geq \beta_{P}$ implying that the loss is greater from disadvantageous relative to the advantageous inequity. Finally it is assumed that $1>\beta_{\mathrm{P}} \geq 0$ ruling out the possibility of getting utility from advantageous inequity. The responder's utility is symmetric and given as follows if the offer $\mathrm{s}$ is accepted:

$$
\mathrm{U}_{\mathrm{R}}=\mathrm{s}-\alpha_{\mathrm{R}} \operatorname{Max}|1-2 \mathrm{~s}, 0|-\beta_{\mathrm{P}}|2 \mathrm{~s}-1,0|
$$

Fehr and Schmidt solve for the equilibrium outcome of the above problem assuming the proposer knows the preferences of the responder. ${ }^{7}$ The equilibrium share is equal to 0.5 if and only if $\beta_{\mathrm{P}}>0.5$, the share will be in the interval s ${ }^{*} \in\left[\mathrm{s}^{\prime}\left(\alpha_{\mathrm{R}}\right), 0.5\right]$ if $\beta_{\mathrm{P}}=0.5$, where $\mathrm{s}^{\prime}\left(\alpha_{\mathrm{R}}\right)=\frac{\alpha_{\mathrm{R}}}{1+2 \alpha_{\mathrm{R}}}$ is the responder's minimum acceptable offer, and the share will equal s' $\left(\alpha_{R}\right)$ if $\beta_{P}<0.5$. This equilibrium is defined in terms of the responder accepting offers. ${ }^{8}$ One can observe easily that the responder will reject any offer $\mathrm{s}<\mathrm{s}^{\prime}\left(\alpha_{\mathrm{R}}\right)=\frac{\alpha_{\mathrm{R}}}{1+2 \alpha_{R}} \cdot{ }^{9}$ Given that rejections of positive offers are frequent leading to a loss to both parties and to a substantial loss in welfare, it would most probably imply that the proposers are miscalculating the $\alpha_{R}$ coefficient. Although this is possible if the preferences are not known to the proposer, it would be an interesting future area of research. Basically, what defines the existence of an equilibrium number of offers not being accepted requires further exploration. As our evidence indicates, many offers were rejected by the responder making both parties worse off.

Figure 5 illustrates the utility frontier assuming that $\beta_{\mathrm{P}}=0.3$ (blue line), $\beta_{\mathrm{P}}=0.5$ (black line) and $\beta_{\mathrm{P}}=1$ (green line). Assuming $\beta_{\mathrm{P}}=0.3$ the frontier is the blue top line. The initial allocation yields a 0.7 utility to the proposer and the responder gets -0.5 utility. Moving towards the right along the frontier the share offered to

\footnotetext{
${ }^{7}$ They also explore the case when preferences are not known.

${ }^{8}$ Proof is shown in Fehr and Schmidt.

${ }^{9}$ The minimum acceptable offer $\mathrm{s}$ is one where the utility of accepting offer is equal the alternative of getting nothing, namely when $U_{R}(s)=s-\alpha_{R}(1-2 s)=0$.
} 
the responder increases. This reduces the utility of the proposer and increases the utility of the responder. ${ }^{10}$ The equilibrium solution is for the proposer to offer 25 percent of the pie to the responder where the blue line crosses the zero value utility for the responder. The responder would reject any offer less than 25 percent since her utility would be negative and thus both parties would be driven to the origin $(0,0)$. This rejection which is common in ultimatum games results in an efficiency loss. In the case where the proposer has dictatorial powers he will offer less than 25 percent of the pie provided $\beta_{\mathrm{P}}<0.5$ and in order to maximize his utility the proposer will keep all the pie to herself. This model breaks down in the case of dictatorial powers since it cannot explain positive offers being made.

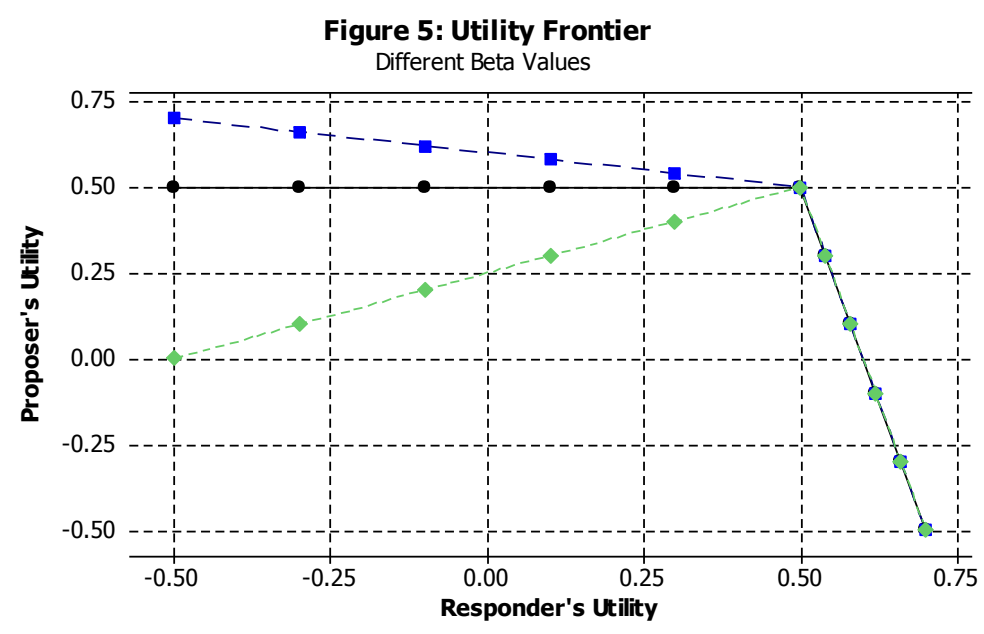

Furthermore, in the self interest model the unique sub-game perfect equilibrium is for the proposer to offer $\mathrm{s}=0$ and the responder to accept this. But are all these equilibrium offers fair from a social prospective or only a subset of these? Let there exist a social welfare function were the social planner selects the share and maximizes the equal weight utilitarian function of the proposer and the responder. The social welfare is:

$\operatorname{Max} U=U_{P}+U_{R}=1-\left(\alpha_{P}+\beta_{R}\right) \operatorname{Max}|2 s-1,0|-\left(\alpha_{R}+\beta_{P}\right) \operatorname{Max}|1-2 s, 0|$

It is easy to observe that the above function is maximized when the share is half of the pie, $\mathrm{s}^{*}=0.5$. Setting $1-2 \mathrm{~s}=0$ yields social welfare equal to unity. If the share is set equal to $\mathrm{s}<0.5$ the social welfare is less than unity, same is true when $s>0.5$. Furthermore, this socially optimal solution is independent of the individual parameters associated with inequality aversion. The social welfare outcome is to share equally the pie. Any other solution is not socially optimal. See frontier above. The social solution achieves both maximum total output and an egalitarian income distribution. This means that the private negotiations fail to achieve the optimal social solution even if fairness considerations are part of the utility of an individual. Individuals are still driven more by greed than by fairness considerations and thus cannot achieve the socially optimal solution. Except in a rare case where the individual has a parameter associated with advantageous inequality is equal to or greater than 0.5 . The social justice system through a tax/transfer policy replaces the optimal solution to $\tau^{*}=0.5-\mathrm{s}^{*}$ and hence the optimal solution can be chosen by setting the tax rate equal to 0.5 .

${ }^{10}$ As the $\beta_{\mathrm{P}}$ increases and equals 0.5 the Proposer' utility is flat at 0.5 until the share equals 0.5 after which it starts dropping. As this parameter increases beyond 0.5 the proposer's utility starts lower than 0.5 and takes a positive slope which implies that his utility increases as the share offered increases until the share is equal to 0.5 . 
The findings of this research are consistent with the existing large body of evidence. We find offers less than 40 percent were highly likely to be rejected. Offers over 40 percent were rarely rejected. Positive offers in the dictator game indicate that individuals assign some importance to fairness. However, we provide additional evidence. First, the dictator's distribution of income is more equitable than the initial distribution and surprisingly very similar to the ultimatum income distribution. Second, rejection of positive offers results in a huge sacrifice of the total value of the economic pie without a substantial fall in inequity. Third, the introduction of a tax/transfer policy results in a more equitable distribution of income and also a smaller loss of the economic pie. Finally, individuals rarely rejected the social justice re-distributive scheme, even though they had the power to do so in the game.

What are the implications of our study? Many labour relation contract disputes are resolved by having a third party involvement such as mediator or an arbitrator. In the presence of the third party, rejections of offers and a strike are less likely to take place. In the political arena, the existence of the United Nation's reduces the chances of war or the outbreak of violence. The tax/transfer system does a better job in providing social justice than an individual's preferences with the addition of fairness considerations. In all these cases efficiency and equity move in the same direction.

In conclusion, the ultimatum game needs to go beyond the issue of the reasons underlying the rejection of the self interest model and to provide a framework where more socially desirable outcomes are achieved.

\section{ACKNOWLEDGEMENTS}

The authors would like to acknowledge all of the Econ 190-02 students, because without their input and participation this project would not have been possible. Financial assistance from the assisted leave committee at TRU is also acknowledged. The authors' names are in lexicographical order.

\section{AUTHOR INFORMATION}

James Seldon received his Ph.D. in Economics from Duke University at age 25. Professor Seldon had a long and accomplished career, spending 10 years at the University of Manitoba, 10 years in the US and finishing his career at Thompson Rivers University. He lived and breathed economics. His specialties were public policy, law and economics, health economics and economics education. Professor Seldon published over 50 referred papers, two textbooks, book chapters and numerous conference proceedings. During the 1990's, he served as the Director of the Business School at TRU. He will be greatly missed as a colleague, mentor and friend.

Peter Tsigaris is an Associate Professor of Economics at Thompson Rivers University, Kamloops, BC, Canada. He teaches introductory economics, statistics, public finance, cost benefit analysis and environmental economics. His diverse research interests span environmental economics, taxation policy and issues, decisions under risk, and economics education. He has presented his research at numerous conferences around the world and published his research in a wide range of peer-reviewed journals. In 2007 TRU awarded Dr. Tsigaris both its Scholarly Merit and Teaching Excellency awards. This was first time both awards have been won by a single faculty member in the same year.

\section{REFERENCES}

1. Andreoni, J. and J. Miller "Giving According to GARP: An Experimental Test of the Consistency of Preferences for Altruism," Econometrica, 2001, 70(2): 737- 753.

2. Bolton, G., and A. Ockenfels, "ERC: A Theory of Equity, Reciprocity, and Competition," American Economic Review, March 2000, 166 - 193

3. Camerer, C., and R. Thaler, "Ultimatums, Dictators, and Manners," Journal of Economic Perspectives, 1995, $209-219$.

4. Dickinson, D., "A Bargaining Experiment to Motivate Discussion on Fairness," Journal of Economic Education, Spring 2002, $136-151$. 
5. Falk, A, and U. Fischbacher, "A Theory of Reciprocity," Games and Economic Behaviour, 2006, 54(2), 293-315.

6. $\quad$ Fehr, E, and K.M., Schmidt, “A Theory of Fairness, Competition, and Cooperation.” Quarterly Journal of Economics, August 1999, 817- 868.

7. Forsythe, R., Horowitz, R, Savin, N.E. and M. Sefton, "Fairness in Simple Bargaining Experiments," Games and Economic Behaviour, May 1994, 6(3), 347-369.

8. Guth, W., R. Scmittberger, and B. Schwarze, "An Experimental Analysis of Ultimatum Bargaining," Journal of Economic Behaviour and Organizations, December 1982, 3(4), 367- 388.

9. Hoffman, E., K. McCabe, K. Shachat, and V. Smith, "Preferences, Property Rights, and Anonymity in Bargaining Games," Games and Economic Behaviour, November 1994, 7 (3): 346 - 380.

10. List, John A., On the Interpretation of Giving in Dictator Games. Journal of Political Economy, 2007, 115(3), .

11. Rabin, M, Incorporating Fairness into Game Theory and Economics," American Economic Review, December 1993, 83(5), $1281-1302$.

12. Roth, A, "Bargaining Experiments," in J. Kagel and A. Roth, eds., The Handbook of Experimental Economics, 253 - 348, 1995, Princeton, N.J., Princeton University Press. 
NOTES 